\title{
The Systems Perspective on the Transformation Towards Sustainability
}

From the systems perspective, the ultimate 'Angst' of societies is the occurrence of 'dystopian' system rupture, which can be the outcome not only of unexpected events leading to the elimination of principles that bind actors together (e.g., identity), but also by purported solutions that create further 'horrendous' events. System ruptures are not only linked with natural hazards such as earthquakes, hurricanes, floods, and pandemics (such as the Ebola outbreak), but also with collapsing national governments and regimes, for example following the outbreak of a popular revolt after a state-sanctioned escalation of violence (e.g., Mubarak's Egypt and Ghadafi's Libya) or an outside intervention (e.g., Saddam Hussein's regime in Iraq following the US intervention).

Assuming that transformation can be either a response to a collapsed system or a preventive effort to avert collapse, this chapter starts by looking at the cognitive aspects of transformation in terms of experiences. In addition, this chapter discusses how energy security reifies transformation, which highlights a major context of the transformation process towards sustainability. Moreover, a special focus on countries with emerging economies will be presented. This selection is set against the backdrop of these countries experiencing multiple parallel transitions that are, to a significant extent, mutually competing. The contextual predicaments (problem contexts) of these countries will be used to understand how impulses for change are both a threat and an opportunity, whereas the difference between a threat and an opportunity is inherently defined by how the states choose to respond and manage changes. Finally, this chapter will suggest policy objectives when addressing, for example, contextual predicaments related to energy security. 
Much of the debate about system ruptures and disruptions is about the importance of an actor (e.g., a country) or an entity (e.g., a bank) to a constructed social system. More illuminating questions emerge as new issues tend to modify existing contexts, agencies, and audiences both in positive and negative terms. What will most likely happen to the system if an actor or entity fails to fulfil its function? Is the cost of helping this actor or entity to get back on track smaller or more tolerable than the expected cost of system ruptures? How do decision-makers assess both the monetary and non-monetary costs of actions and non-action? How will the system 'reboot'?

Moreover, other questions pertain to how changing power configurations allow individual actors and entities to gain preference when reshaping the existing order. Is the stability of the global system and order threatened by China as an emerging superpower? Or is China the necessary agent of change by assuming global leadership that can bring motion (and growth) to a global system that has stagnated and has become fragmented? How will China's ambitious development campaign, the Belt and Road Initiative, which is backed by 40 billion US dollars from the New Silk Road Fund, 900 billion US dollars from China's Development Bank, and 100 billion US dollars from the Asian Infrastructure Investment Bank (see Menon 2017; Philipps 2017) define international relations, particularly after the withdrawal of the United States from the TPP and the Paris Climate Agreement? How will sustainable low carbon transformation be embedded in China's long-term policy objectives? Or is sustainable development the long-sought-after principle that can bring China to the next level?

In addition, linking the discourse on system ruptures to transformation processes remains a huge challenge. While it is widely accepted that changes are imminent if not necessary for growth or even survival, it is a huge conceptual and methodological challenge to decide whether an impulse (or a trigger) is part of this imminent system change that ensures the relevance and functionality of the system, or if it is already the first step in a system rupture. Furthermore, there is a diversity of meanings and ramifications of such an impulse. For example, the massive decrease in coal prices could be an impulse to enhance the expansion of renewable energy. But for some coal-dependent countries such as Poland and the Czech Republic or other regions within a country such as Kentucky, West Virginia and Ohio in the United States, this impulse is not only a significant threat, but it mobilizes radical agents who have now found new channels to reverse other advancements such as in welfare and human rights. 


\subsection{System Transformation and Human Cognition-Power and Identities}

The conceptualization of system transformation needs to begin by looking at the cognitive and behavioral aspects of changes (see Brewer \& Stern 2005; Messner et al. 2013). Collectivities that represent people respond to changes by transforming themselves. While some experts, such as Anthony Robbins (2006), equate change with growth, others highlight 'distress' when addressing transformations (see France 2013; Benson et al. 2014). For example, Karl Polanyi (2015) reiterates that a "great transformation" is the result of a collapse of the system. Furthermore, as this chapter argues, a transformation process is likely initiated when (at least) one of the three streams (policies, polities and politics) experiences at least one of the following symptoms of cognitive vulnerability: disengagement, dismantling, disidentification, disenchantment and disorientation.

Disengagement pertains to the loss of connection to the specific environment, whereas 'connection' means a sense of purpose and personal growth. For example, when the decline of profitability of coal technology had led to a significant loss of employment, private households may have experienced disengagement as they were forced to seek employment in other places or in other sectors, leading to the loss of their routines and comfort zones. Arguments that the renewable energy sector means new jobs do not mean anything concrete for those previously employed in coal mining industries, not only because of differences in qualifications, but also because of how they have built their identities.

Dismantling refers to vulnerability during transitions, where temporary structures are not able or are no longer able to provide the perception of stability and security. Vulnerability connotes the loss of control and autonomy. For example, the transition period that foresees a shift in the dominant use of fossil fuels to renewables may produce 'disturbing' vacuums due to a lack of experience around how challenges caused by transition can be effectively addressed. For example, the Energiewende in Germany led to a significant increase in electricity bill prices for private households leading to a perception of inequity, as most industrial and business entities were exempted from newly introduced levies to support the renewable energy sector.

Disidentification occurs when roles and status are no longer able to provide the same purpose (such as stability and security) that they have provided in the past, 
leading to a loss in the meaning of identities. The sense of belonging defines identity and its loss brings distress. Addressing a loss of identity requires an understanding of the 'stories' and narratives behind such representations. Through this, a more adequate understanding of how identities can be open or resistant to changes can be achieved. For example, when owning gasoline-intensive SUVs is no longer seen as a status symbol, individuals will have the chance to see the impractical aspects of owning such vehicles. This requires, however, the decoupling of status from emission rich cars by producing luxurious cars with less emissions.

Disorientation is the absence of perspectives or direction. A sense of purpose is translated into actions, leading to the achievement of goals. Actions, however, require a plan or a (road)map that serves as personal leverage for beliefs and behavior. Without a map, a sense of less certainty of actions will more likely arise. Disorientation reinforces insecurity, because caveats such as norms and values that have served as orientation for social relations often lose their meanings. For example, local communities affected by massive job loss may witness increased level of antipathy towards policy-makers, who are unable to effectively address the causes of job loss. Discredited policy-makers can become the targets of various forms of violence.

Depending on how inclusive (collaborative or positive-sum) or divisive (competitive or negative-sum) the decision-making processes are, some actors may, for example, use 'dogmatic' arguments to assert their interests, appealing to issues of higher political priority. For example, in 2010, vindicating the dominance of the market logic in German policy-making, five German car companies, supported by the then German Federal Minister of Economy Michael Glos, argued that lowering the threshold value for $\mathrm{CO}_{2}$ emissions from cars to 120 grams per kilometer by 2012 will lead to elimination of jobs in Germany (Schulte von Drach \& Schätzl 2010). In this case, 'change agents', such as environmental NGOs and social groups, are deprived of effective arguments, because as non-economic entities, they are unable to provide compelling arguments using market logic. Resistance to changes that are compelling is not constructive, especially when the 'success' of this resistance is merely defined by the perception of power. Depending on how effective groups protecting the interests of conventional energy are, implementing energy policies conducive to climate protection goals requires a broader consensus-building framework where consensus will not be merely dependent on the inability of dissenting actors to organize resistance, but rather on the notion that cooperation provides more gains (compared to non-cooperation). 
Nevertheless, when considering the power resources available to societal groups, the successful transformation of systems needs to find ways to integrate the interests of societal groups irrespective of their power resources. In addition, identities may exist that do not correspond to that of the system. Often, it is assumed that a given system reflects one identity and that changing systems imply equally changing identities, which is misleading. For example, coal mining is deeply embedded in the social identity of many local communities. While the majority of the communities are enthusiastic in welcoming new job opportunities that are created through renewable energies, climate policies that aim to reduce emissions by closing coal mining pits are then perceived as targeting their communities, hence, their identities.

Therefore, energy policies promoting non-conventional energy also need to address the narratives behind these identities, which will require more time and different types of interventions or incentives. There is co-evolution within and between levels, processes at multiple dimensions and levels unfolding simultaneously (Hughes 2009), and these levels often have different paces of transformation (Braudel 1958). These processes may compete or reinforce each other, making decision-making more complicated and requiring a well-orchestrated integrated approach. As Frank Geels and Johan Schot (2009: 22) argue, transitions come about when processes link up and reinforce each other. This focus on the linkages of processes deviates from technology-push approaches, which can be found in punctuated equilibrium frameworks.

\subsection{System Transformation-'Grasping' the Context of Sustainable, Low-Carbon Transformation}

The historicity of the transformation process needs to put the focus of analysis on the meaning of collected decisions or actions for the system. From the system perspective, historicity can define and provide an understanding of self-driving dynamics as well as 'fatal synergies.' Various subsystems such as governance, institutions, and civil society may have deficiencies which, when analyzed separately and individually, can be tolerated by the system in specific contexts (and not in others). However, when these deficiencies are combined over the course of the transformation process towards sustainability, they produce additional obstacles that pose additional conceptual and methodological challenges. For example, the lack of channels to formally and materially integrate political opposition into government, combined with structural inequalities in society and the high upfront costs of renewable energies, may increase the need for the security of 
sophisticated facilities and high-tech equipment (further increasing the costs of maintenance), as the lack of political integration into a specific context may have created and reinforced the use of paralegal means, wherein attacking expensive facilities becomes an effective means of leverage.

System transformation, as a non-linear process, is not self-evident and not self-enforcing. When changes remain unmanaged, shocks may lead to partial or total collapse of the system, thus, producing vacuums and uncertainty. Its management requires quantifiable indicators that could serve as 'benchmarks' to eventually decide on adjustments in priority areas. Quantification, in turn, necessitates appropriate procedures of data collection and content analysis as well as a clear definition of the units of analysis (components, sequences or complete models), encoding categories and the interpretation of data to determine patterns. Nevertheless, quantitative methods, which aim to eliminate coincidences, are confronted by the historicity of the transformation process leading to conflicts.

The difficulties in analyzing sustainable low carbon transformation processes are similar to the difficulties in analyzing historical events, with the distinct purpose of deriving lessons for other cases. Often, the comparison of different country cases with the intention of learning from the 'successful' (often developed country) in order to 'help' the less successful (often developing country) is trapped in the 'center-periphery' dichotomy, limiting the acceptance and even applicability of these lessons. Mainly following 'the center is capable, the periphery is not' evolutionary narrative is frequently misleading, at least in its methodological function. As natural sciences may suggest, the individuality of historical events often undermines the scientific validity of historical analyses due to limitations in the generalizability and applicability of results. In addition, comparing the low carbon transformation of countries is often rejected due to claims of Eurocentric perspectives (see Fisher \& Green 2004; Najam 2010).

Furthermore, when 'green technology' becomes the dominant agenda of a country's foreign policy, green technology is inevitably geo-politicized as it indirectly changes existing power relations between relevant countries, making it predominantly a mere subject of power games. For example, applying lessons from the "successful" German Energiewende (energy system transition) to developing countries is often regarded by critics as "a new form of imperialism." The German Energiewende was officially introduced after the Fukushima reactor incident in 2011 and was vindicated by challenges brought about by the Russian-Ukrainian conflict. It defines changes in Germany's policies and initiated the transformation of the country's energy system to a system with the increased use of renewable energies and energy efficiency technologies (see Ciuta \& Klinke 2010; Die Bundesregierung 2016). Because the Energiewende is regarded as a result 
of the geopolitical and energy security discourse in the country, its application to other (mainly developing) countries which did not undergo the same discursive process implies latent coercion. As such, as claimed by Felix Ciuta and Ian Klinke (2010), the Energiewende has increasingly dominated and framed the debate on the domestic and external policies of Germany and has eventually defined the German geopolitical narratives. Germany has become a major proponent of renewable energies and energy efficiency technologies in various international forums, whereas, countries with a high dependence on conventional energies are pushed to the 'periphery' through these forums. In addition, Germany's international aid support, both from government agencies as well as from German NGOs, has increasingly become related to the promotion of renewable energies in developing countries, while the narrative "climate protection is sustainable development policy" has increasingly defined foreign and developmental policies (BMZ 2015).

\subsection{Transition, Transformation and Leapfrogging- Sustainable Low Carbon Policy Priorities in Countries with Emerging Economies}

Academic and political discourses about the transitions, changes and transformations of energy systems have been revived in the assessment of measures to mitigate climate change. The Fifth Assessment Report of the Third Working Group, in summarizing their results, claim that stabilizing greenhouse gas (GHG) concentrations will require large-scale transformations in human societies, from the way energy is produced and consumed to how the land surface is used (Clarke et al. 2014). Furthermore, Thomas Bruckner et al. (2014) raise the issue that the energy infrastructure in most developing countries is still undeveloped and not diversified. Therefore, energy system transformation will involve incremental costs. Nevertheless, while this may be the case, especially in the Least Developed Countries (LDCs), other developing countries such as Brazil, China, Turkey, India, Mexico, Indonesia and the Philippines do have the technical and financial capacity to deploy renewable energy technologies (La Viña 1997; van Asselt \& Gupta 2009; Rong 2010). In fact, not only is China currently the biggest investor in renewable energy, the deployment of renewable energy technologies is also a top policy priority of the government (Feng Wang \& Haitao Yin 2010; Mathews \& Hao 2013).

There is a consensus that the any mitigation regime will need to address the requirements of energy systems, particularly of developing countries with 
emerging economies. As the UNFCCC (1992) identifies, preventing dangerous anthropogenic climate change will only be feasible with substantial emission reductions below the business-as-usual case in developing countries (Jakob \& Steckel 2013; Jakob et al. 2014). While this consensus also recognizes that the sustainable low carbon transformation of energy systems of developing countries should not hamper economic development, the international community is fragmented when it comes to how economic development should define the emission reduction goals of developing countries (Najam et al. 2003; Winkler et al. 2009b). Some governments argue that developing countries have the right to emit all necessary emissions for the sake of economic development (Zhang \& Cheng 2009; Lotfalipour et al. 2010; Ozturk \& Acaravci 2010). Others argue that although developing countries should be given the right to emit emissions, the level of emissions should not surpass the average level that was reached by developed countries. Michael Jakob et al. (2014) suggest that reducing emissions in developing countries will require a fundamental break in the historical correlation between economic growth and GHG emissions.

The prospect of decoupling economic development from GHG emissions has become a popular notion. As Fred Pearce (2016) points out in an article in The Guardian, the International Energy Agency of the OECD has reported that global $\mathrm{CO}_{2}$ emissions from energy-related activities have not risen since 2013, staying at 32.1 billion tons even as the global economy grew. As Pearce suggests, this implies the possibility of decoupling emissions from economic activity. This decline was led by China and the United States, which are the two largest emitters and which both registered declines in emissions of about 1.5 percent. Moreover, the decoupling is mainly attributed to the higher pace of increased deployment of renewable energies. The Frankfurt School of Finance and Management confirms that in 2015, more than twice as much money was invested into new capacities for renewables than into new power stations using fossil fuels. In addition, for the first time, the majority of this investment was in developing countries, with China responsible for 36 percent of the total global investment (Pearce 2016). Decoupling is therefore already on its way and has reached a stage in which renewable energy deployment has become self-enforcing.

\subsubsection{Leapfrogging of the Developing Countries-A Way Forward?}

An argument was presented by several governments in developed countries and by epistemic communities that developing countries should not follow the "dirty" 
economic development path made by developed countries. Instead, these developing countries should take advantage of 'leapfrogging', which is both more economical and lower in carbon. Technologies and financing models are already available to enable leapfrogging. However, while this is the case in theory, such a transformation of the global energy system would impose considerable additional costs on developing countries (Jakob et al. 2014). If developed countries decided to shoulder the costs of energy system transformation, a further question would be raised about the channels used to transfer the money. The first notion that usually comes into the picture is that this transfer is a development aid. There is a separate debate about developmental aids and how providing aid to developing countries is often defined by self-serving interests rather than the wish to support development (see Tandon 2008), not to mention the so-called "climate rent curse" through which financial inflows negatively affect the recipient's long-term economic performance (Jakob et al. 2014). Yash Tandon (2008) further argues that the conceptual understanding of developmental aid is dominated by the notion that the donors own the process. This notion would lead to additional conflict cleavages in any energy system transformation process where, unlike in the donor-recipient dichotomy, developing countries expect to own the process.

The concept of leapfrogging was originally developed in the field of industrial organization and economic growth. The main idea behind the concept is that small and incremental innovations are the responsibility of a business company wanting to dominate the market. As of more recently, the concept of leapfrogging is used in the context of sustainable development and energy system transformation, particularly for developing countries, as a theory of development which may accelerate progress by skipping inferior, less efficient, more expensive or more polluting technologies and industries and move directly to more advance ones. As José Goldemberg (1998) argues, by avoiding the mistakes made by developed countries, developing countries can circumvent environmental and socially harmful stages of development and do not need to follow the polluting development trajectory taken by industrialized countries.

Major challenges for the leapfrogging of developing countries to attain a sustainable and low-carbon energy system include the issues of knowledge/technology transfer and capacity-building, that is, how to help developing countries to build up new infrastructure, acquire knowledge and technological expertise, and formulate relevant policies in line with sustainable development and climate protection. Furthermore, the leapfrogging country needs to build an 'enabling environment' that includes good governance and the availability of local technical expertise that fosters innovation from within (see Zerriffi \& Wilson 2010). Innovation should also be supported by an innovative culture, whereas innovation is 
the ultimate mantra of local entrepreneurship (Carraro \& Siniscalco 1994; Lundvall et al. 2011). Innovation should also serve as the major driver of production and consumption that cuts across various sectors of the economy.

Another major challenge for leapfrogging to attain sustainable and low-carbon energy is how social inequalities can be reduced. Susan Cozzens and Raphael Kaplinsky (2009) note that innovation and inequality co-evolve, with innovation sometimes reflecting and reinforcing inequalities and sometimes undermining them. Innovation is only seldom seen as a potential driver of social and economic justice. Mitigation measures, including deploying renewable energies, could contribute to further deficits in public acceptance because of adverse distributional impacts. However, leapfrogging to attain sustainable and low-carbon energy, when managed properly, can also pose opportunities for reducing inequality. For example, individuals with lower incomes tend to be more dependent on public transportation than individuals with higher incomes. While leapfrogging is possible and feasible, both technologically and financially, why is it that some countries still opt to follow the "dirty" path? This book argues that the technological and financial feasibility of leapfrogging is not enough to entice the shifting of energy systems. There is a need to address transformation as a process of decision-making. Which requirements should be fulfilled, from the decisionmaking perspective, to enable the switch?

\subsection{Problem Context: Energy System Transformation in Developing Countries with Emerging Economies}

What makes the energy system transformation of countries with emerging economies different to those of developed countries and other groups of developing countries? Why is it worth analyzing? What is the value of learning the specificities of energy system transformation in developing countries? If no substantial emission reduction schemes will be relevant, developing countries are expected to follow China's carbon-intensive economic growth pattern and this will make any drastic emission reduction in developed countries unable to achieve the $2{ }^{\circ} \mathrm{C}$ target agreed by the international community (IEA 2011). As Michael Jakob et al. (2013) observe, households from selected developing countries with an income of the average European household exhibit a carbon footprint similar to that of the average European. In addition, richer households, for example from India, Indonesia and the Philippines, have considerably higher carbon footprints than poorer ones (Jakob \& Steckel 2013; Seriño 2014) which suggests that income is the most 
important driver of variations of emissions over time and between households (Jakob et al. 2014). As such, the demand of developed countries that developing countries substantially limit their emissions, implies limiting the increase of income.

Moreover, putting pressure or even blaming the developing countries to the failure to reach the $2{ }^{\circ} \mathrm{C}$ target is not only unfair (La Viña 1997; Beyerlin 2006; Penetrante 2010), it is also counterproductive. For once, developing countries will not accept any emission reduction scheme which limits income growth. As carbon-intensive energies have traditionally met energy demand, there is a close correlation between human development and GHG emissions (Costa et al. 2011). No developed country has managed to achieve high levels of economic development without having crossed a threshold in final energy consumption of approximately 40 GJ per capita (Steinberger \& Roberts 2010; Steckel et al. 2013). Expecting or even forcing developing countries to refrain from following the same path under business as usual conditions is not only inequitable, it is also not feasible (Najam et al. 2003; Winkler et al. 2009b).

Nevertheless, as already highlighted in this book, it is possible to decouple emissions from economic development. Leapfrogging can be viable in developing countries, particularly for those with emerging economies, if they are not left alone with the issues related to the transition processes. As Michael Jakob et al. (2014) argue, in a similar way to developed countries, per capita emissions in developing and emerging countries will only stabilize or decline at comparatively high income levels. Therefore, the question that needs to be asked is how developing and emerging countries can transform their energy systems before reaching high income levels. Leapfrogging will require substantial financial support to cover the incremental costs.

Developing countries with emerging economies will need to simultaneously manage various transitions in a shorter time frame than the developmental trajectory taken by developed countries. As increased income will call for social, cultural, and other types of changes that are beyond the economic sphere and developing countries with emerging economies will need to employ a holistic approach in policy-making. For example, these countries tend to experience more intense changes in demography, such as massive urbanization as job opportunities become more concentrated in bigger cities, internal migration and displacement as new infrastructures will require the relocation of communities, and some qualifications becoming obsolete as new types of expertise are demanded, among others.

In addition, developing countries with emerging economies tend to act as experimental grounds for new technologies that require maturation. As new 
technologies are deployed in non-OECD countries, new conflict cleavages arise as these technologies clash with existing cultural and societal conditions. Technological development is often driven by a specific societal need and deploying this technology to a different society will require significant adaptation. With no prior practical experience available, the current state of progress of deploying new technologies in these countries remains bleak, a "black-box" dilemma. Public acceptance of technologies is a process that can take time and forcing the deployment of these technologies without substantial public acceptance will not only make the deployment costlier, the deployment will remain uncertain as minor problems can easily be transformed into reasons to cancel deployment.

\subsection{A Systems Perspective on Energy Transitions- Energy Policy Objectives for Countries with Emerging Economies}

For any given energy policy objective, decision analysis is useful when analyzing the multiplicity of policy options and of policy evaluative criteria and can help policy-makers assess the trade-offs and synergies associated with one or a combination of policies. Countries with emerging economies will need an integrated outlook on policy objectives. This section analyzes the challenges of energy policy-making in countries with emerging economies. It also provides recommendations for how these challenges can be resolved.

\subsubsection{Policy Objective 1: Increase Energy Access and Energy Efficiency by Reducing Income Gaps Between Urban and Rural Areas}

One major barrier for many developing countries in ensuring universality of energy access is the gap between urban and rural incomes. A common trend in these countries is rapid urbanization, where opportunities are concentrated in cities (Kusno 2000; Grubler et al. 2012). Providing energy, such as electricity and the required infrastructures in rural areas, is often not cost-effective due to the lack of possibility of economies of scale. Under current conditions, private investment in energy projects in rural areas will be in most cases limited, because these projects are not expected to yield profits. Therefore, providing energy in rural areas will most likely involve certain amounts of subsidies. With many 
low-income households living in rural areas, government subsidies will be needed to avoid high energy costs being forwarded on to low income households. While subsidies are often seen as not sustainable and inhibiting innovation, rural communities will continue to require government assistance to ensure that rural areas will have access to a similar quality of living as in urban areas.

From the estimated 1.2 billion people (17\% of the global population) who did not have access to electricity in 2013, more than $95 \%$ of this 1.7 billion lived in countries in sub-Saharan Africa and developing Asia. In China, 1 million people are without electricity. In India, 237 million people (19\% of the total population, $26 \%$ of the rural population) do not have access to electricity (IEA 2015). The Philippines (21 million), Indonesia (49 million), Bangladesh (60 million), Vietnam (3 million), and Pakistan (50 million) are the other countries identified as EAGLE or N-11 countries with emerging economies (IEA 2015) with a huge portion of their population still without access to electricity. Providing access to these people will most likely lead to an increase in the national level of emissions but will at the same time promote the achievement of certain sustainable development goals (e.g. gender equality, affordable and clean energy).

In addition, the massive inflow of new residents into megacities will often require upgrades in energy infrastructures in urban areas to catch up with the increasing energy demand. The trend towards urbanization, now standing at 3.7 billion people, is expected to accelerate and double by 2050. Furthermore, $96 \%$ of all urbanization by 2030 will occur in developing countries (Runde 2015). This shift will create additional challenges to providing food, water and energy. Policies that aim to ensure a reliable energy supply will cut across other priorities. Paradoxically, in many developing countries, there is often the sentiment that cities tend to be major recipients of government spending, successfully competing for funds that could have been spent in the peripheries. In many developing countries, this sentiment fuels separatist movements, right and left-wing extremism, and further exacerbates social distrust.

Moreover, as cities become more congested, the more difficult and cost-intensive it will be to expand existing infrastructures. It becomes more difficult for governments to prioritize other policies than those that support, for example, energy efficiency. For example, in a highly populous city with a very high housing demand, governments will most likely prioritize providing affordable housing rather than low-carbon housing. Energy efficiency programs offered by governments such as tax cuts for solar panels on roofs will most likely experience resistance from the society as such programs are seen to favor high-income households and real estate property owners. In addition, with a very high demand 
for rental housing, property owners will have low or no motivation to refurbish in order to meet energy efficiency goals, as they will not personally benefit from such investments. Low-efficiency rental houses and apartments will easily find tenants in highly populated urban areas.

Governments in emerging countries need to identify a scenario that addresses the dilemma of policies that aim to increase energy efficiency and policies that aim to expand energy access. Incentives and other types of market instruments are available to avoid policies promoting energy efficiency from obstructing the state's ability to effectively provide other welfare services. Furthermore, policies should focus on co-benefits and synergies as promoting energy efficiency can lead to additional benefits such as job creation, health improvement, pollution control, entrepreneurship and local community development.

\subsubsection{Policy Objective 2: Capacity Building for Energy Transitions}

It is widely accepted that there is no one-size-fits-all strategy for capacity development. Efforts need to be tailored to the specific attributes of a given continent, region, country, and even sub-national region (Armitage 2005; Mytelka et al. 2012). The energy system transition of developing countries in the context of climate mitigation usually implies the need to build local capacity through technological, knowledge-based and financial transfer. Such a transfer intends to help developing countries in building local expertise and financial capacity to deploy necessary technologies for low-carbon development (see WBGU 2009). Michael Jakob et al. (2012) estimate these financial transfers will reach almost 400 billion US dollars by 2020 . They further claim that this amount is comparable with many developing countries, raw material exports. In this regard, many experts argue that the rationales behind raw material export might be assumed in financial transfers leading to similar negative effects related to the so-called 'resource curse' or 'Dutch disease' (van der Ploeg 2011; Kornek et al. 2013). In addition, Ulrike Kornek et al. (2013) observe that countries that receive the highest transfers are generally confronted with low institutional quality as indicated by deficits in the rule of law and the control of corruption. Therefore, policies related to capacity building in the context of energy transition should adequately address their negative effects on local state-building processes.

Furthermore, to ensure the contextual relevance of their strategies, the ownership of capacity building as a process needs to be taken up by the recipients. 
Capacity building often involves technology or knowledge transfer which implies the existence of the dichotomy of "donor" and "recipient", where the donor tends to be developed countries and the recipient developing ones. There is a need to find a concept for the capacity building of developing countries which is not based on the current OECD-Development Assistance Committee (DAC) vocabulary and their definitions of aid, which have also been adopted by the United Nations (see Tandon 2008). Furthermore, the new concept of technological, knowledge-based and financial transfer in climate mitigation should not be an extension of the 0.7 percent Official Development Assistance (ODA) model, which was adopted by the United Nations in October 1970. Public discourse about the responsibilities of developed countries towards developing countries has used this ODA model as a yardstick for measuring developed countries' commitment to the advancement of developing countries (Tandon 2008). The new concept of capacity building in the context of climate mitigation and low-carbon energy system development needs to be based on equal partnerships and cooperation.

Thus, technology transfer to build the capacities of developing countries to achieve successful energy transformation needs to have the perspective of an asymmetrical cooperation, where interdependence between the donor and the recipient defines the "mutual" relationship of the donor and recipient. The differing and often non-comparable commitments of developed and developing countries do not need to hinder cooperation. Only when the donor is dependent on the success of realizing the objective of the transfer can the recipient occupy an equal rank and therefore co-own the process. In addition, when the receiving country can reciprocate the transfer, the transfer ceases to involve the recipient as an object of generosity or charity. The benefits of energy transformation in developing and emerging countries should be clearly documented in order for developed countries to recognize that their efforts benefit them as well, and not, as many experts see it, that the capacity building of developing countries with financial commitments to developed countries is unfair to future generations of developed countries (Schelling 1995).

Reciprocity is therefore a key element that policies need to adequately address. This means that any international program that aims to support energy transformation in developing and emerging economies should also encompass provisions for reciprocating technology or knowledge transfer from the developing country to the developed country. For example, technology transfer projects tend to involve experts from developed countries coming to developing countries to build capacities. Reciprocity should promote experts from developing countries 
coming to developed countries not only for training purposes, but also to allow them to build capacities, for example, in developed countries with aging infrastructures. This would allow experts from developing countries to gain experience as well as international recognition. When the direction of technology transfer is two-way, additional benefits can be gained. Energy policies should therefore build on partnership and cooperation that aims to achieve mutual gains rather than mere developmental aid, which is often driven by vested interests and donor ownership of the process. Developing countries should also seek cooperation with other developing countries through South-South partnerships.

\subsubsection{Policy Objective 3: Reduce the Environmental and Human Health Impacts of Energy System Transformation}

A critical outlook on energy system transformation in countries with emerging economies includes a critical analysis of measures that are considered solutions. Renewable energies, such as biomass, may undermine food security and/or biodiversity. Wind mills may, for example, negatively affect ecosystems including bird migration routes (see GWEC 2010; Wiser et al. 2011). The necessity of expanding smart grid systems enormously may pose health problems to the population living near the high-voltage grids (see IRENA 2013). In addition to mitigation costs and potentials, the deployment of energy-related mitigation measures will depend on a variety of other factors that relate to broader economic, social and environmental objectives, driving policy choices and decisions in the relevant sectors. The implementation of energy-related mitigation measures can have positive or negative effects on these other objectives. To the extent that these side-effects are positive, they can be deemed as co-benefits. But if these side-effects are adverse and uncertain, they imply risks. Co-benefits and the adverse side-effects of mitigation measures, the associated technical risks and uncertainties, as well as their public perception and technological spill-overs can significantly affect investment decisions, individual behavior, and policy-maker priorities.

Developing and emerging countries' energy policies need to look at the technical, social, economic, and environmental risks of relevant measures, such as the deployment of renewable energies, the expansion of smart grid networks, etc. Particularly in liberalized energy markets, governments have to ensure that standards are met and that companies will take responsibilities when risks materialize. 


\subsubsection{Policy Objective 4: Accelerate the Rate of Energy-Related Technological Change}

Innovative policy plays a central role in accelerating the rate of energy transformation (see Markard \& Truffer 2008b; Mission Innovation 2015). It is fundamental in stimulating and managing the processes of knowledge generation, application, dissemination, and feedback that are involved as the transformation process unfolds. Policies supporting the supply of innovations or the development of technologies include investments in $\mathrm{R} \& \mathrm{D}$, intellectual property protection, laboratory and testing infrastructure, training and skills, university-industry collaborations, formal and informal mechanisms of knowledge exchange, technology roadmaps to guide the direction of innovation, and financial incentives such as tax credits for private investment.

A major challenge to coming up with effective innovation policy is that it cuts across various jurisdictions. Policy instruments promoting investments in R\&D are often addressed by the ministries responsible for research, technology, education or trade \& industry. Intellectual property protection is addressed by the ministry responsible for justice, peace and order; training and skills by the ministry for education. Financial incentives are most likely provided by the ministry for finance or the ministry for economy and trade. In addition, in most developing countries, universities and other centers of higher learning tend to be run by private institutions and enjoy a significant degree of autonomy, as such establishing collaborations between universities is difficult if not unwanted, because of the highly competitive environment. Cooperation frameworks between universities and industries are also often not yet evident in developing countries, especially when local industries tend to cater to foreign markets.

Energy system transformation must be complemented by integrated policies that seek to promote innovation to effectively absorb the contingencies of technological change. Energy system transformation also needs to be complemented by expanding the domestic market, as innovation is a direct result of solving local problems. When a country's industrial sector is raw material export-oriented, which is typical of most developing countries, the required impulses that trigger innovation tend to be far-fetched.

Furthermore, policies should address cultural elements of technological change. Innovation is often the result of technological development responding to concrete societal needs. When innovation is exogenous, it might clash with local culture. For example, Ilse Ruiz-Mercado et al. (2011) note that the adoption of improved biomass cook stoves, which will not only improve the health conditions 
of households but also reduce emissions from developing countries, will depend on public acceptance. For many indigenous communities in Mexico, fire is an important symbol, and cooking practices that limit seeing the fire will tend not to be used. Therefore, policies that aim to promote technological change need to assess the level of public acceptance of the deployment of various technologies. Technological change requires an 'innovative culture' where the society is receptive to innovation.

\subsubsection{Policy Objective 5: Coordinate and Implement International and National Energy-Related Policies}

Globalization poses both risks and opportunities to a country's energy system transformation. A major instrument to promote energy transformation is direct, foreign investment in the energy sectors in developing countries. However, because imminent issues in many developing countries revolve around providing access to electricity in rural areas, foreign direct investment remains unattractive for foreign investors as these fields do not promise significant returns. Furthermore, foreign direct investment may also pose risks to the country's energy security goals.

Furthermore, as a vast array of agencies and structures are responsible for various aspects of energy sector governance, the national government requires a high level of institutional capacity to coordinate and facilitate interactions between the government agencies responsible for various elements of the energy sector. Many developing countries are confronted with political fragmentation in which government positions have been allocated based on the political interests of political parties and groups and not on technical expertise. This leads to crucial government agencies having other interests beyond their formal mandate. In addition, government agencies often compete for limited public resources.

Moreover, due to their wide-ranging and often cross-sectoral responsibilities, many government officials lack detailed knowledge of sustainable energy technologies, their economics and financial requirements, and alternative mechanisms for their effective support (see Ochs et al. 2015). There is also often the lack of a significant capacity dedicated exclusively to energy issues, often making it difficult to coordinate with other government officials and to provide the updated information necessary for renewable energy planning. Finally, the transformation of energy systems requires clarity in final decisions in the energy sector and that this final decision will be continued by subsequent governments or administrations. Thus, a broad general political consensus is inevitable. 


\subsection{Interim Conclusion-So What? Where Do We Go from Here?}

This chapter highlighted the historicity of transformation processes, it focused on the cognitive aspects of transformation towards sustainability and explained how these aspects frame the set of possible actions. In addition, this chapter explained the systemic contextuality of policy-making by focusing on countries with emerging economies as well as on energy security as a major policy goal. The contextual predicaments (problem contexts) of these countries were used to understand how impulses for change are both a threat and an opportunity, whereas the difference between a threat and an opportunity is inherently defined by how the states choose to respond and manage changes. The chapter ended by recommending policy objectives when addressing, for example, contextual predicaments related to energy security.

From a systems analytical perspective, there are many reasons why developing countries, particularly those with emerging economies, find it difficult to commit to a low-carbon and sustainable energy system. As highlighted in this chapter, these reasons include the lack of a holistic and integrated perspective due to a failure of re-visiting existing assumptions, which was highlighted in chapter 4. In addition, after chapter 3 provided the understanding of how structural imbalances are unintentionally reproduced due to existing critical junctures, this chapter further explored the specificities of these imbalances by analyzing how human cognition reinforces such imbalances.

Finally, this chapter problematized the failure to consider co-benefits in calculating the costs and benefits of low carbon energy policies. As argued in this chapter, the possibility of decoupling emissions from economic development and some of the trade-offs between energy security and climate protection could be resolved, both of which are integral aspects of sustainable development. The policy objectives presented in this chapter use the premise of such decoupling to advance transformation towards sustainability. 
Open Access This chapter is licensed under the terms of the Creative Commons Attribution 4.0 International License (http://creativecommons.org/licenses/by/4.0/), which permits use, sharing, adaptation, distribution and reproduction in any medium or format, as long as you give appropriate credit to the original author(s) and the source, provide a link to the Creative Commons license and indicate if changes were made.

The images or other third party material in this chapter are included in the chapter's Creative Commons license, unless indicated otherwise in a credit line to the material. If material is not included in the chapter's Creative Commons license and your intended use is not permitted by statutory regulation or exceeds the permitted use, you will need to obtain permission directly from the copyright holder.

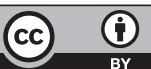

